not the advantage of Sir H. Thompson's intimate acquaintance with the case, but were entirely dependent on Dr. Knox's account of it, and as the latter acted as Liston's assistant at the operation, we thought his report of it likely to be correct; but it appears from Sir Henry's letter that the account given in the catalogue of the College of Surgeon's Musenm differs from that of the eye-witness of the operation. Dr. Knox says that Mr. Liston's view of the case was that "a cyst or false membrane of the form of the bladder itself occupied, as he conjectured, the interior of the bladder and, were this removed by operation, the patient might recover ; " and then later on in the same report Dr. Knox states "with a straight sharp-pointed bistoury, which he usually carried in his waistcoat-pocket, he (Mr. Liston) opened the bladder above the pubes, and as the incision proceeded there escaped from the bladder a foreign body resembling a cyst or false membrane, as he and I concluded it to be, and of the shape of the interior of bladder." Now here we have an account of the diagnosis of a morbid growth in the bladder and a deliberate operation for its removal, and consequently it is a question whether Sir $\mathbf{H}$. Thompson is historically accurate when he states that " the so called 'tumour' was simply an exfoliation of the mucous membrane, and was met with by him (Mr. Liston) when tapping an old man for retention from prostatic disease." 'Though it is true that this was not strictly a tumour of the bladder, it is perfectly true that Liston diagnosed some cyst in the bladder, and as such proceeded to remove it ; and consequently we maintain that when dealing with the history of such an operation as the removal of tumours from the bladder this case is worthy of a place, inasmuch as the operator when dealing with it undoubtedly considered that he had to do with a disease analogous to, if not identical with, true cysts. We quite agree, from the account given of it by Dr. Knox, in thinking with Sir H. Thompson that the case was not as Liston thought it- "a cyst or false membrane," but a case of exfoliation of the entire mucous membrane of the bladder.

In conclusion, we can but express the hope that our ex planation is satisfactory to Sir H. Thompson, and assure him that we also "welcome fresh evidence in favour of the new method of examining and operating in obscure vesical disease." We are, Sir, yours obediently,

Dec. 8th, 1883 . WALTER WHITEHEAD. BILTON POLLARD.

\section{ARREST OF THREATENED MAMMARY ABSCESS.}

To the Editor of THE LANCET.

SIR, - In cases of threatened mammary abscess, I have for many years, with very successful results, given three consecutive doses of ten grains of quinine at intervals of twelve hours, at the same time using the usual local application of belladonna. The administration of quinine in these cased, although its anti-suppurative power is well known, is not practised by anyone with whom I have conversed, but I have myself found it so successful that I think it deserves to be in general use, especially as the disease is so painful and so exhausting to the system. The best cases for the treatment are those occurring during lactation, and it is less suitable immediately after labour. It is unsuitable if the bowels are confined and the tongue furred. There are some patients who do not bear such large doses of quinine, in which case a first dose of ten grains may be followed by two of five grains each. I originally saw this treatment recommended in a French medical journal, and claim therefore no originality. I have frequently seen the pain and tenderness disappear within forty-eight hours, although a little hardness will remain for some days or longtr, and the inflammatory symptoms may recur, and may be again at once checked by the same treatment. A recurrence, however, is rendered less likely if the belladonna is continued for a time, although pain has ceased. No doubt some will say that the success of the treatment is owing to the belladonna and not to the quinine. I used the belladonna for years before I used the quinine in addition, and was struck with the greater rapidity and certainty of the result when the quinine also was used. At the same time $I$ admit the difficulty, when two drugs are employed, of apportioning to each its real value. - I am, Sir, yours truly.

Loeds, Nov. 1883.

\section{PHYSIOLOGY OF THE THYROID GLAND.}

\section{To the Editor of THE LANCET.}

Sir,-General attention having been drawn to the phy. siology of the thyroid gland, in consequence of the recent interesting discussion on myxoedema at the Clinical Society, I may perhaps be allowed to mention some facts in the histology of the gland which have an important bearing on its function. A series of researches on this subject, which I have made under the direction of Dr. Klein, and which are published in the Philosophical Transactions of the Royal Society for 1876 and 1881, have shown, amongst other things, that not only is a homogeneous or finely granular viscid material (termed "colloid") found in the vesicles of the tbyroid gland, but that a substance morphologically identical with this is found in the lymphatics, with which this organ is very richly endowed. It is therefore reasonable to conclude that a material is formed in the vesicles which is carried off by the lymphatics of the organ. I have further shown that the colloid material in the vesicles is largely formed by the destruction of red blood.corpuscles which have entered the vesicles, as red blood-corpuscles are frequently found in the vesicles in all stages of disintegration and decolorisation-in fact, in such a state as to show beyond doubt that they had entered during life. There is therefore, no doubt, I consider, that the thyroid gland exercises some general influence over the composition of the blood. Why a deposit of mucin should take place in the tissues in cases of myxodema and cachexia strumipriva (supposing these two diseases to be analogous) is more difficult to explain, but it may be suggested that if the elimination of "colloid" material or its constituents from the blood be prevented by excision or atrophy of the thyroid gland, a transudation of these substances into the connective tissue generally may take place. This presupposes that on its way back to the circulation through the lymphatics the colloid material becomes changed in character. This is, of course, only theory, and must be taken for what it is worth. My object at present is to draw attention to some of the already ascertained facts of the histology and function of the gland. As soon as opportunity offers I intend to continue my researches in this direction.

I am, Sir, yours obediently,

E. CResswell BABER, M.D. Lond.

Western-road, Brighton, Dec. 3rd, 1833.

\section{"SPORADIC CRETINISM."}

\section{To the Editor of THE LANCET.}

SrR,-With regard to the correspondence in your last number upon sporadic cretinism in relation with absence of the thyroid, communicated by Sir William Gull, I beg, with due deference to this great authority, to offer a few remarks, more especially upon its pathology. During two years' residence as medical officer to the Asylum for Idiots, Earlswood, it was my good fortune to meet with many of these cases; and as feebleness of intellect (not infrequently amounting to complete idiocy) is the mental condition of those afflicted, their admission into Earlswood and their absence from the cliniques of general hospilals is easily accountable. The late Dr. Hilton Fagge, who made several visits to the above institution, clearly observes that their physical condition presents a remarkable unity of appearance, so much so that they bear a close ramily relation; the analogy is true of their mental condition, and anyone acquainted with the type can predict with a fair amount of accuracy, judging from past experience, what advance a child in this condition is likely to make under a special system of education.

The presence of tumours above the clavicles (the so-called latent thyroid), and the abeence of the normal thyroid are not necessary concomitants of sporadic cretinism-indeed, they appear to be the exception ; for in a number of post. mortems performed by me during that period I do not remember an instance of a complete absence of the normal thyroid. My late colleague, Dr. Grabham, now Commis. sioner in Lunacy for New Zealand, made a post-mortem in a case of sporadic cretinism where there was a true goitrous enlargement. This condition is deseribed as not uncommon in endemic cretinism. We must thus look elsewhere for the true cause of this peculiar condition; and it is unlikely that 